\title{
Microstructure and Surface Morphology of Nanocrystalline Silver Silicates
}

\begin{abstract}
S. DUHAN*
Materials Science Lab, Department of Materials Science and Nanotechnology, Deenbandhu Chhotu Ram University of Science and Technology, Murthal, Sonepat-131039, India

(Received May 19, 2011; in final form January 6, 2012)

Microstructure and surface morphology of $\mathrm{AgO}$ nanocrystallites $\left(25 \mathrm{~nm}\right.$ ) supported on $\mathrm{SiO}_{2}$ and subjected to heat treatment in air up to $500^{\circ} \mathrm{C}$ have been studied by transmission electron microscopy, scanning electron microscopy, and the Fourier transform infrared spectroscopy measurements. It has been found that heating at $500{ }^{\circ} \mathrm{C}$ resulted in spreading of $\mathrm{AgO}$ over silica and formation of quasi two-dimensional amorphous phase (silicate precursor) exhibiting very weak band at $566 \mathrm{~cm}^{-1}$ have appeared in the Fourier transform infrared spectroscopy. Nanocrystalline silver silicate of undefined structure formed at $300-500{ }^{\circ} \mathrm{C}$.
\end{abstract}

PACS: 61.46.Df, 61.46.Hk, 78.67.Bf

\section{Introduction}

Synthesis and characterization of nanosized metallic powders have attracted attention of the materials community due to their promising properties. Metallic nanoparticles have many potential applications such as heterogeneous catalysts, surfaces of heat exchangers, thermometers at ultra low-temperatures, memory devices, gas sensors, optical switches etc. $[1,2]$. Their use in several natural and inorganic materials has been used as antimicrobial agents [3]. However, among them, silver or silver ions have been long known to have widespread antibacterial activities [4-6]. Therefore, there have been a broad range of commercial usages of silver or silver ions as antibacterial agents.

Materials containing metal nanoclusters have traditionally been prepared by a variety of chemical or physical methods. Among various methods, sol-gel has been largely used for the preparation of inorganic oxide, due to its versatility and low cost. In this method, the synthesis of materials starts from precursors and oxide network is obtained via hydrolysis and condensation reactions that occur in solution. This method allows the incorporation of different species such as atoms, molecules or ultrafine particles into dried glass. These species are added in the precursor solutions producing characteristic properties in solid-glasses. The optical properties of silica based nanocomposites, synthesized using chemical process, depend on the type and amount of the incorporated species [7-14]. In recent past, the physical properties of silica glass containing the different amounts of silver were discussed [15-17]. Recently, it has been shown that silica glasses containing certain amounts of silver, prepared by sol-gel method, can be crystallized in cristobalite phase at annealing temperatures much lower than $500{ }^{\circ} \mathrm{C}$ predicted by the phase diagrams.

In the present report, we have studied effect of calcinations temperature with prolonged annealing time that

* e-mail: surender6561@yahoo.co.in mainly supports the development of the silver silicates nanocrystallites in case of silver-containing silica. The stem of this study is in the results of our earlier report [18], in which we demonstrated the effect of temperature and time on $\mathrm{Nd}_{2} \mathrm{O}_{3}-\mathrm{SiO}_{2}$ nanocomposites. The annealing temperature and time dependence of the formation of $\mathrm{Nd}_{2} \mathrm{O}_{3}$ nanocrystallites as well as their distribution in fused silica matrix were observed. We found that the average size of the silver nanocrystallites in a silica matrix was $\approx 25 \mathrm{~nm}$. The scanning electron microscopy (SEM), transmission electron microscopy (TEM), and the Fourier transform infrared (FTIR) spectroscopy data for silver silicates are presented.

\section{Experimental}

\subsection{Preparation of bulk samples}

The principle and basic technique of the sol-gel process were described in detail in Ref. [18]. Silver silicates were prepared by mixing high purity reagents $\left(\mathrm{CH}_{3} \mathrm{CH}_{2} \mathrm{O}\right) \mathrm{Si}$ tetraethoxy silane (TEOS) (Aldrich 99.999), ethanol (Aldrich 99.9995), and deionized water. To prepare the samples, the molar ratio of starting solution was taken as TEOS: $\mathrm{AgNO}_{3}: \mathrm{H}_{2} \mathrm{O}: \mathrm{HNO}_{3}: \mathrm{C}_{2} \mathrm{H}_{5} \mathrm{OH}$ was 1:0.2:11:0.5:8. The $\mathrm{pH}$ of resultant solutions was three. The resultant homogeneous solutions were filled in a mold and placed in drying oven at $25^{\circ} \mathrm{C}$. The gelation occurred after 9 days. After gelation the samples were still left inside the oven for 20 days, for ageing, until no shrinkage appeared. Thermal treatments were then done in air, at different temperatures $\left(200,300,400\right.$, and $\left.500^{\circ} \mathrm{C}\right)$ and time $(1 \mathrm{~h})$.

\subsection{Characterization}

The particle size and aggregation state of particles were further measured with transmission electron micrograph (TEM, JEOL, JEM-1010, Japan) at $80 \mathrm{kV}$ accelerating voltage. Infra red spectra in the wave number range 2000-400 $\mathrm{cm}^{-1}$ were recorded with a FTIR spectrometer (Perkin Elmer 1600). SEM of the samples was done with JEOL-JSM-T330-A 35 CF microscope at an accelerating voltage of $20 \mathrm{kV}$. 


\section{Results}

\subsection{FTIR}

Figure 1 shows the infrared absorption spectra, in the range $500-4000 \mathrm{~cm}^{-1}$, and treated at the indicated temperatures 300,400 , and $500^{\circ} \mathrm{C}$. For annealing temperatures $300^{\circ} \mathrm{C}$, samples showed three absorption bands centered at about 450,800 , and $1050 \mathrm{~cm}^{-1}$, which are the most important peaks related to $\mathrm{Si}-\mathrm{O}-\mathrm{Si}$ bonds $[19,20]$. These peaks are related to the bending vibration, symmetric and stretching vibration modes of this bond, respectively. For the spectra of samples heated at $400{ }^{\circ} \mathrm{C}$, there is also a shoulder peak at about $1636 \mathrm{~cm}^{-1}$ which is related to the $\mathrm{Si}-\mathrm{O}-\mathrm{Si}$ bond [1].

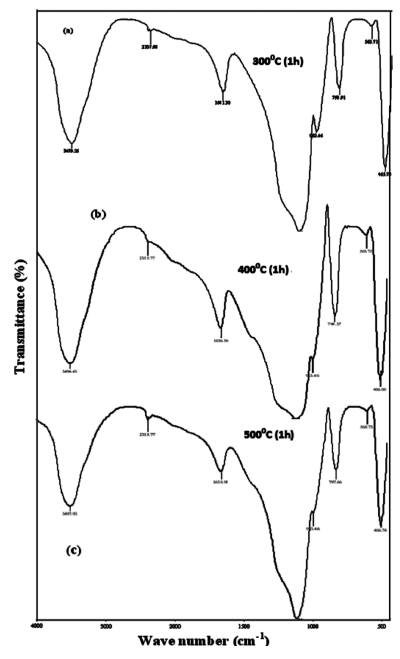

Fig. 1. FTIR spectra of silver doped in silica matrix at different temperatures: (a) $300{ }^{\circ} \mathrm{C}$, (b) $400{ }^{\circ} \mathrm{C}$ and (c) $500^{\circ} \mathrm{C}$.

In addition, an additional sharp absorption band appeared at about $625 \mathrm{~cm}^{-1}$, assigned to TO- $A_{2}$ symmetry modes. The spectra of samples heat treated at $500^{\circ} \mathrm{C}$ show an example of the deconvoluted absorption band (Si-OH). The bands at 1070 and $1200 \mathrm{~cm}^{-1}$ have been previously associated with TO and LO optical modes in the $\mathrm{SiO}_{2}$ structure, respectively [19]. The bands at about $950 \mathrm{~cm}^{-1}$ in samples heated at $500^{\circ} \mathrm{C}$ are associated with stretching vibrations of $\mathrm{Si}-\mathrm{OH}$ groups [20]. This band is dramatically reduced in samples heated at higher temperatures. The absence of nitrate peak at about 1300 $1400 \mathrm{~cm}^{-1}$ and organic bond related peaks show that all of the nitrate and organic groups are burned and removed from the system during thermal treatment. There is a peak at $3409 \mathrm{~cm}^{-1}$ which is related to the $\mathrm{H}_{2} \mathrm{O}$ groups.

It can be seen from Fig. 1 that peak at $566 \mathrm{~cm}^{-1}$ has appeared in the FTIR of silica due to the Ag doping. In the FTIR spectra this peak can be seen with higher intensity which is a result of thermal treatment of the sample at higher temperatures.

\section{2. $S E M$}

In order to study the morphology of heat treated samples, SEM micrographs are shown in Fig. 2. Micrograph (a) (calcined at $200^{\circ} \mathrm{C}$ for $1 \mathrm{~h}$ ) shows the morphology of amorphous Ag-doped silica. The structure of amorphous Ag-doped silica (dark patches) is similar to thick lamellar structure. With increasing temperature (micrograph (b), calcined at $300^{\circ} \mathrm{C}$ for $1 \mathrm{~h}$ ) the content of water molecule, $\mathrm{Si}-\mathrm{OH}$ and volatile materials decreases, which confirms the initial phase of crystallinity of the silver oxide in silica matrix. The structure of patches (silver oxides/silicates) is irregular. In order to overcome the problem of nonuniform distribution/dispersion, the introduction of glass modifiers such as aluminum or phosphorus in silversilica binary system shall be the subject of further consideration. Micrograph (c) (calcined at $400{ }^{\circ} \mathrm{C}$ for $1 \mathrm{~h}$ ) shows that all the dark patches were replaced by white patches due to concentration quenching of silver oxide in silica matrix and their size ranging $30-80 \mathrm{~nm}$. Finally thermal treatment of the sample (micrograph $(\mathrm{d})$ ) at comparatively high temperature $\left(500^{\circ} \mathrm{C}\right)$ for prolonged sintering $(1 \mathrm{~h})$ provides much improved crystallinity and dispersion of silver in a fused silica matrix. One may note that, in this micrograph, the structure of agglomerated particles is similar to rod shaped and thick lamellar quasi-spherical shape may be identified as silver silicates and their size is in the range $15-80 \mathrm{~nm}$. These observations also support FTIR data of the corresponding condition. This micrograph indicates that the microstructure of silver doped silica powder prepared by sol-gel technique can be favorably controlled by selecting correctly both the heat treatment time and temperature.

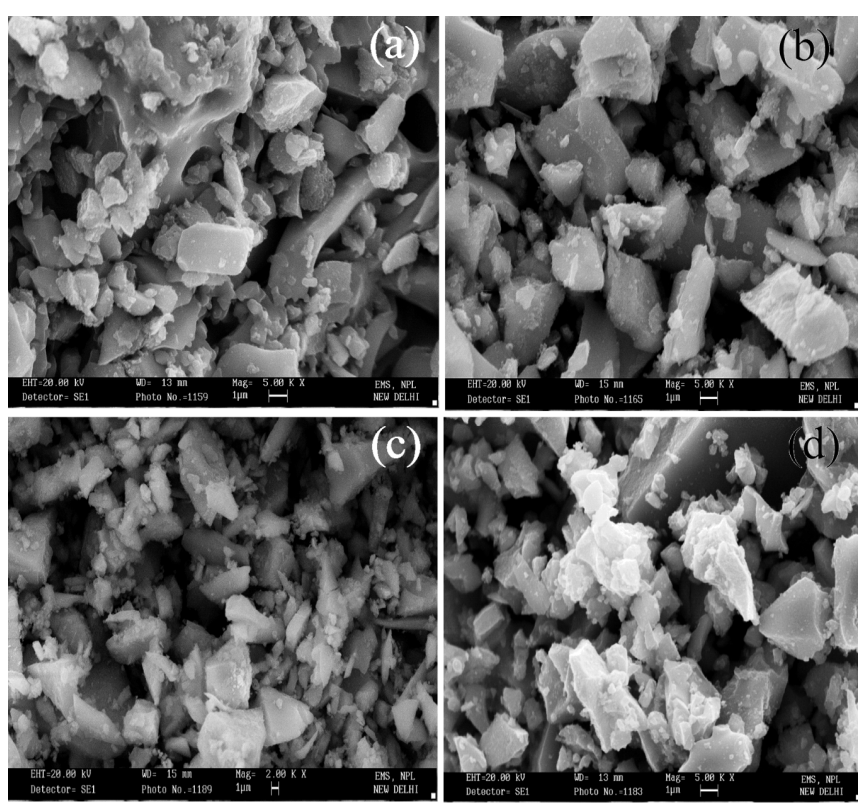

Fig. 2. SEM micrograph of silver doped in silica matrix at different temperatures: (a) $200{ }^{\circ} \mathrm{C}$, (b) $300{ }^{\circ} \mathrm{C}$, (c) $400{ }^{\circ} \mathrm{C}$ and (d) $500{ }^{\circ} \mathrm{C}$. 


\section{3. $T E M$}

The TEM spectra of the samples annealed at $300^{\circ} \mathrm{C}$, $400^{\circ} \mathrm{C}$, and $500{ }^{\circ} \mathrm{C}$ are shown in Fig. 3a-c, respectively. Figure 3a shows agglomerates of small grains and some dispersed nanoparticles which are more or less spherical. Figure $3 \mathrm{~b}$ shows particles spherical and close to the square for the large ones. Figure $3 \mathrm{c}$ shows agglomerates of small grains and some dispersed nanoparticles. The particle size of silver particles (right-hand illustration in Fig. 3) shows that the particles range in size from 8 to $50 \mathrm{~nm}$ with mean diameter $24 \mathrm{~nm}$.

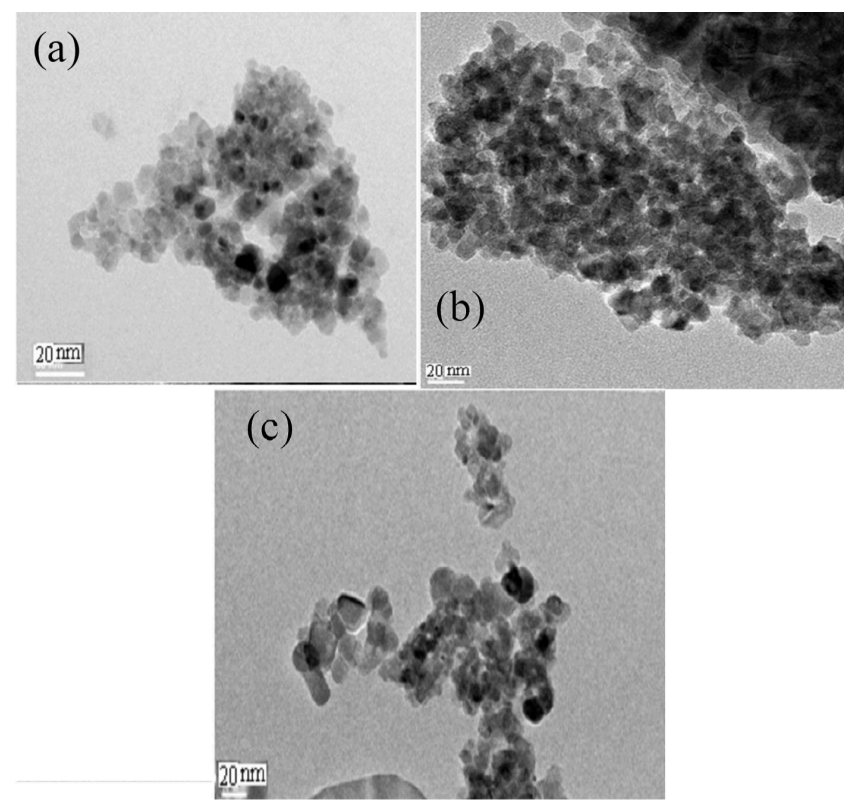

Fig. 3. TEM pictures of silver doped in silica matrix at different temperatures: (a) $300{ }^{\circ} \mathrm{C}$, (b) $400{ }^{\circ} \mathrm{C}$ and (c) $500{ }^{\circ} \mathrm{C}$.

\section{Discussion}

Silver silicates were successfully prepared by the solgel technique and characterized by FTIR spectroscopy, SEM and TEM. The heat treatment forms silver doped in silica nanocrystallites in the range $25-45 \mathrm{~nm}$ in the sample. The presence of IR band at around $950 \mathrm{~cm}^{-1}$ for the $400{ }^{\circ} \mathrm{C}$ dried gels (Fig. 1) confirmed the presence of non-bridging oxygen other than those belonging to $\mathrm{Si}-\mathrm{OH}$ groups. With the increase of temperature, the densification of silicate network was followed by elimination of residual organics; mainly carbon and water were formed by condensation reaction. It is also noticed that silver clusters formed at $500{ }^{\circ} \mathrm{C}$ are stable and do not show any degradation of their optical properties with aging.

In relation to the surface morphology of the samples and the annealing temperature, in this system, high temperature treatment leads to a semi circle-like morphology of $\mathrm{Ag} / \mathrm{SiO}_{2}$ clusters (Fig. 2). TEM results showed that the aggregates around these circles are Ag-rich areas. It seems that these semi-circle-like pores are created due to the exhaust of the gases resulting from nitrate decomposition to the formation of Ag-rich clusters around these pores.
Work is in progress on the characterization of the non-linear optical properties of the obtained samples.

\section{Conclusions}

The sol-gel process successfully prepared silver-doped silica samples. The samples were characterized by FTIR spectroscopies, SEM and TEM, and the formation of $\mathrm{Ag} / \mathrm{SiO}_{2}$ nanocomposites was confirmed. It is found that the morphology and evolution of the system as a function of the annealing temperature is necessary for obtaining a nanoclusters distribution in silica matrix.

\section{References}

[1] F. Gonella, P. Mazzoldi, Handbook of Nanostructured Materials and Nanotechnology, Vol. 4, Academic Press, CA 2000.

[2] P. Chakraborty, J. Mater. Sci. 33, 2235 (1998).

[3] H.J. Jeon, S.C. Yi, S.G. Oh, J. Biomater. 24, 4921 (2003).

[4] S.M. Lee, B.S. Lee, T.G. Byunc, K.C. Song, J. Colloids Surf. A: Physicochem. Eng. Aspects 355, 167 (2010).

[5] http://microbewiki.kenyon.edu/index.php/Silver as an Antimicrobial Agent, access on Oct. 2010.

[6] U. Klueh, V. Wagner, S. Kelly, A. Johnson, J.D. Bryers, J. Biomed. Mater. Res. Part B: Appl. Biomater. 53, 621 (2000).

[7] B. Akkopru, C. Durucan, J. Sol-Gel. Sci. Technol. 43, 227 (2007).

[8] M.R. Poulsen, P.I. Borel, J. Fage-Pedersen, J. Hubner, M. Kristensen, J.H. Povlsen, K. Rottwitt, M. Svalgard, W. Svendsen, Opt. Eng. 42, 2821 (2003).

[9] A. Dhawan, J.F. Muth, Nanotechnology 17, 2504 (2006).

[10] E. Cattauruzza, G. Battaglin, F. Gonella, G. Mattei, P. Mazzoldi, R. Polloni, B.F. Scremin, Appl. Surf. Sci. 247, 390 (2005).

[11] T.P. Ma, M. Miyauch, Appl. Phys. Lett. 75, 88 (1999).

[12] R.A. Weimer, P.M. Lenahan, T.A. Marchione, Appl. Phys. Lett. 51, 1179 (1987).

[13] F. Orgaz, H. Rawson, J. Non-Cryst. Solids 82, 378 (1986).

[14] A. Duran, J.M. Hernaz-Navarro, P. Mazon, A. Jogar, J. Non-Cryst. Solids 82, 391 (1986).

[15] A. Hinsh, A. Zastrow, J. Non-Cryst. Solids 147, 579 (1992).

[16] M. Menning, J. Spanhel, H. Schmidt, S. Betzholz, J. Non-Cryst. Solids 147, 326 (1992).

[17] D. Brusilowsky, M. Eyal, R. Reisfeld, Chem. Phys. Lett. 153, 203 (1998).

[18] S. Duhan, P. Aghamkar, Acta Phys. Pol. A 113, 1671 (2008).

[19] F.L. Galeener, A.E. Geissberger, Phys. Rev. B 27, 6199 (1983)

[20] M. Ristic, M. Ivanda, S. Popovic, S. Music, J. Non-Cryst. Solids 303, 270 (2002). 